\title{
ways of knowing
}

New from Chicago

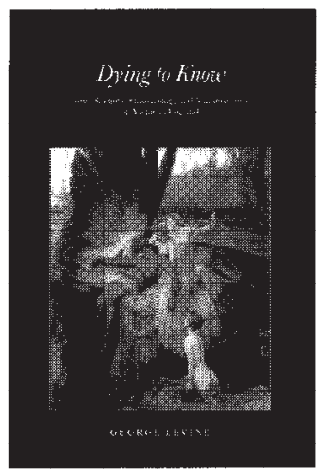

\section{Dying to Know}

Scientific Epistemology and Narrative in Victorian England George Levine

"Brings contemporary literary studies into an unprecedented dialogue with the history and theory of epistemology. Disclosing the ways in which even the most stringent ideals of objectivity have relied on narrative form and ethical concepts, Levine then revisits nineteenth-century narrative literature and shows its distinctive contributions to the history of thought on knowledge and objectivity. The result is a profound and brilliantly illuminating study."-Amanda Anderson, The Johns Hopkins University

"Dying to Know is deeply felt and passionately argued. It will be provocative, controversial, and influential reading for scholars of nineteenth-century literature and culture."-Mary Poovey, New York

University

cloth $\$ 45.00$
The Romantic

\section{Conception of Life}

Science and Philosophy in the Age of Goethe

\section{Robert J. Richards}

"A masterful synthesis, the clearest, most vigorous, and most convincing presentation of the foundations of Romantic biological theory available. Readers will find here not merely a penetrating analysis of the conceptual issues, but also a rich and vivid account of the major protagonists' lives and interactions. I can think of no more direct access to the core achievement of the Age of Goethe than this engaging and provocative study."-David Wellbery, author of The Specular Moment: Goethe's Early Lyric and the Beginnings of Romanticism

Cloth $\$ 35.00$

\section{The Wild Girl, Natural} Man, and the Monster Dangerous Experiments in the Age of Enlightenment

Julia V. Douthwaite

"Gives sparkling new readings of classic Enlightenment themes concerning body and mind, will and morality, education and human perfectibility. Nicely illustrated, this book guides the reader through the philosophies, practices, fears, hopes, and conundrums of eighteenth-century human science and experimental culture."-Londa Schiebinger, author of Nature's Body Paper $\$ 19.00$

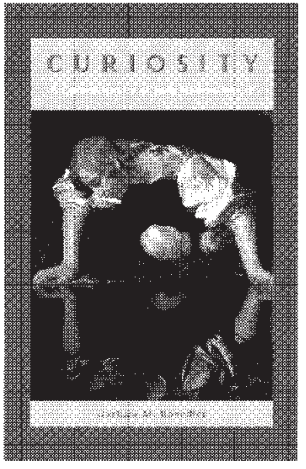

Now in paper

\section{Curiosity}

A Cultural History of Early Modern Inquiry

\section{Barbara M. Benedict}

"Robinson Crusoe told us that his head was always filled 'with rambling Thoughts.' That is how he got into such trouble, but it is also the way he survived. Rambling thoughts, as Benedict shows in this exuberant study, were at the center of English literary and cultural experience from the late seventeenth to the early nineteenth centuries. Transgressive, uncontrollable, hopelessly vulgar and at the same time exalted and ennobling, the passion of curiosity was the key that unlocked the sensibility of modernity in its great formative age."-Stephen Greenblatt

Paper $\$ 25.00$ 


\section{The Bedford Anthology of}

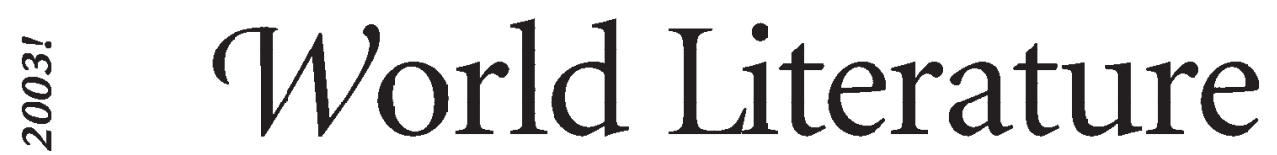

Paul Davis, Gary Harrison, David M. Johnson, Patricia Clark Smith, and John F. Crawford, all of University of New Mexico

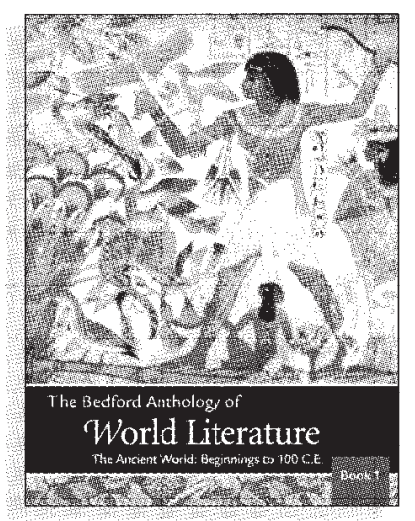

1650 - The Present Package B - Paperbound

Book 4 (The Eighteenth Century, 1650-1800) Book 5 (The Nineteenth Century, 1789-1917) Book 6 (The Twentieth Century, 1900-The Present)

Available February 2003

This new anthology contains the tools students need to read, comprehend, and enjoy the best the world has to offer - including thematic groupings of literature from all over the world; social and historical contexts, comparative timelines, abundant maps, hundreds of images, and much more. It's the first anthology to acknowledge the wide geographical and chronological range of material students are being asked to cover in the world literature course - and then do something about it.

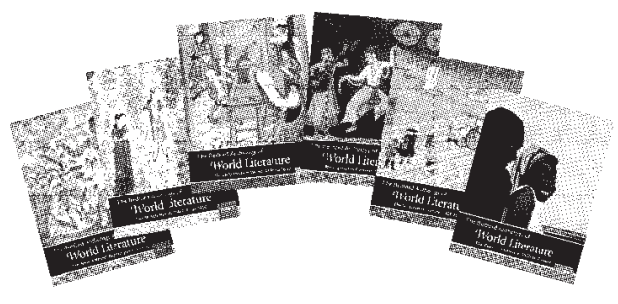

\footnotetext{
\begin{tabular}{r|r} 
For & visit: bedfordstmartins.com \\
Copies & e-mail: sales_support@bfwpub.com
\end{tabular}
}

\section{Earliest Recorded Literatures - 1650} Package A - Paperbound

Book 1 (Ancient Literatures, 3,000 B. C. E. - 100 C. E.)

Book 2 (The Middle Period, 100-1450)

Book 3 (Early Modern Literatures, 1400-1650)

Available July 2003

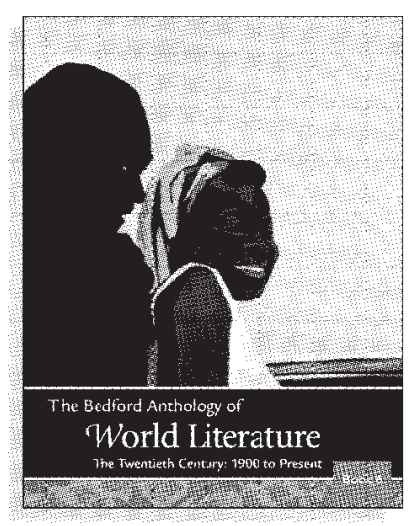

- Six paperback books - available in two packages or as individual texts - correspond to the six periods most commonly taught. Each book features a striking twocolor design that showcases the literature, highlights pedagogical features, and sets off the many maps and illustrations to best effect.

- Superb collection of complete longer works, plays, prose, and poems represents the best literature of all time available in English or English translations from around the globe. Unique "In the World" clusters emphasize social and historical contexts.

- Practical and accessible editorial apparatus helps students understand what they read and allows them to place literature in a larger context. Resources inside the anthology include Time and Place boxes, Bibliographies, Connections questions, and a Glossary of Literary and Historical Terms. An extensive Instructor's Manual and a rich Web site, World Literature Online, provide additional support. 